\title{
Quality Assurance with Dosimetric Consistency of a Co-60 Teletherapy Unit
}

\section{Num Prasad Acharya, Tika Ram Lamichhane and}

\section{Bidyapati Jha}

Journal of Nepal Physical Society

Volume 4, Issue 1, February 2017

ISSN: 2392-473X

Editors:

Dr. Gopi Chandra Kaphle

Dr. Devendra Adhikari

Mr. Deependra Parajuli

JNPS, 4 (1), 88-92 (2017)

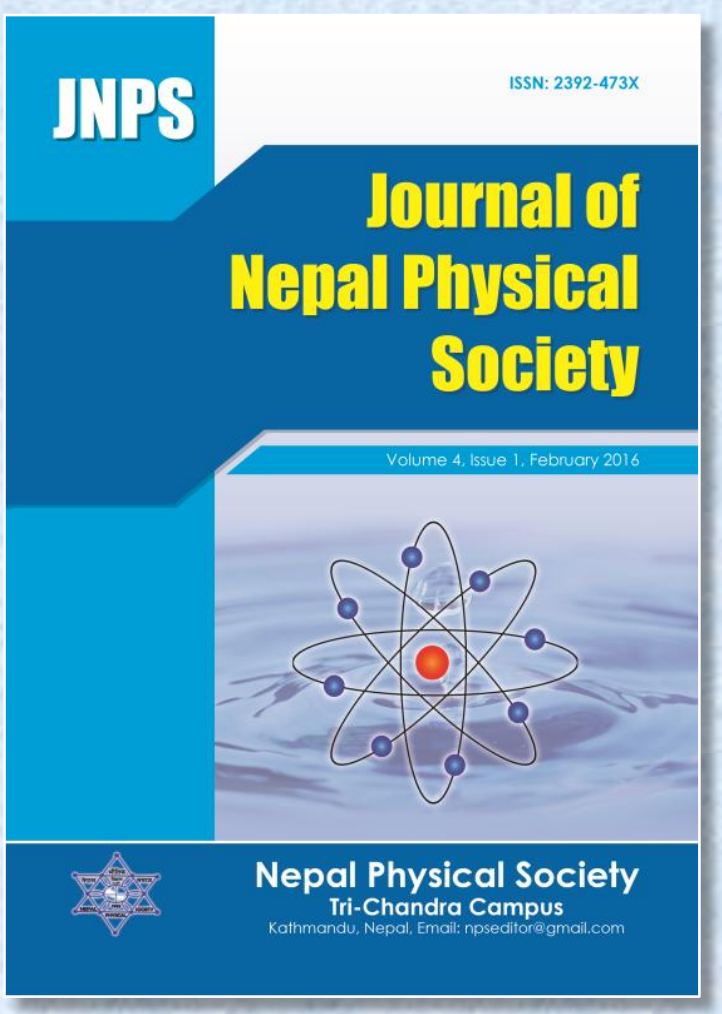

Published by:

Nepal Physical Society

P.O. Box : 2934

Tri-Chandra Campus

Kathmandu, Nepal

Email: npseditor@gmail.com 


\title{
Quality Assurance with Dosimetric Consistency of a Co-60 Teletherapy Unit
}

\author{
Num Prasad Acharya ${ }^{1}$, Tika Ram Lamichhane ${ }^{\mathbf{1}^{*}}$ and Bidyapati Jha ${ }^{2}$ \\ ${ }^{1}$ Central Department of Physics, Tribhuvan University, Kirtipur, Nepal \\ ${ }^{2}$ Department of Radiotherapy, Bhaktapur Cancer Hospital, Bhaktapur, Nepal \\ *Corresponding Email: trlamichhane@tucdp.edu.np
}

\begin{abstract}
It is essential to know the standard dose rate, output of Co-60 source in the radiation treatment periodically. It is because the over dosage may cause radiation hazards where as under dosage may lead to unsatisfactory treatment of cancer. Present study focused on the radiation standards and dosimetry for the assurance of the quality and verify that the output of the ionizing radiation emitting medical instruments such as Teletherapy Unit (TTU) which should be within $\pm 2 \%$ of the stated one. Present study was done as a part of the regularity of quality assurance (QA) of telecobalt radiotherapy unit that includes the dosimetric measurements of Co60 TTU at Bhaktapur Cancer Hospital (BCH), Bhaktapur per each month from 29 March 2012 to 29 December 2014. The radionuclide source is Co-60 which has been incorporated in TTU, BCH for the purpose of therapeutic treatment of cancer. The Co-60 source decays continuously to Ni-60 (half-life of 5.27 years) with the decrease in its activity and hence the output dose rate. The calculations of actual dose rate of Co-60 TTU were done by the source to surface distance (SSD) technique. It has been concluded that there is a quality assurance management in Co-60 TTU, BCH with the consistency in the average output dose rate obtained by the actual dosimetry values and the expected output values obtained by decay method. The values obtained by actual dosimetry are within $\pm 2 \%$ of the expected values so that the deviation of the actual output dose rate from the expected output data lies within the permissible limit as prescribed by International Atomic Energy Agency (IAEA) and International Commission on Radiation Units and Measurement (ICRUM). In conclusion, our study shows a trend towards uniform and better dose delivery from Co-60 TTU, BCH, Nepal.
\end{abstract}

Keywords: Quality Assurance, Dosimetry, Teletherapy Unit, Output Dose, Consistency, ICRU, IAEA.

\section{INTRODUCTION}

The major role of radiotherapy is in the treatment of cancer in which $50 \%$ of the cancer patients receive radiotherapy as a primary treatment or in the combination with other treatment methods for cure or palliation (Kunkler et al., 2003; IAEA, 2006). Radiotherapy is focused on maximizing the radiation dose to tumor cells whilst ensuring minimal dose to normal tissues for safety of the health personnel. The types of radiation used for cancer treatments are x-rays, $\gamma$ - rays and accelerated charged particles. Both $\mathrm{x}$-rays and $\gamma$ rays are electromagnetic radiations, but they differ only from their origin. The x-radiation used for cancer treatment is produced from a linear accelerator or from a high energy x-ray unit by hitting a target metal such as tungsten or tantalum with highly accelerated electrons. During nuclear transitions or decay of some radioactive materials like cobalt-60, $\gamma$-rays are emitted from the nucleus. Upon falling the ionizing radiations like $\mathrm{x}-$ or $\gamma$ rays on the living cells, it may cause genetic disorder by disturbing the coding system of gene or it may break the side chains of Deoxyribonucleic Acid (DNA) causing the cell death. Moreover, the cellular compounds important for survival and reproduction of the cells can also be damaged. The therapeutic treatment of cancer implies the killing of malignant cells using ionizing radiation. However, the killing of tumor cells eventually leads to the protection of the vital cells from infections (UNSCEAR, 2010; Prasad et al., 2007).

About a century ago, $\mathrm{x}$-rays and radioactivity were discovered which led a revolutionary advancement in diagnosis of body affects with medical imaging and in therapy of chronic diseases like cancer. In the middle of twentieth century, megavoltage photon energies are available from betatrons, Co-60 
$\gamma$-rays and linacs. The increased power of photon penetration and skin sparing provides new opportunities to the radiation oncologist for optimizing the patient treatment. In recent years, several reports have considered various issues which define the optimum photon energy for the treatment of malignant disease. Although Co-60 has been mentioned as a suitable radiotherapy source, it has not been widely used in radiation therapy departments in our country, Nepal. Considering Co60 as an old modality, it is only useful for palliative treatments in a large department or for developing countries with limited technical resources. One of the strongest arguments against Co-60 has been the unsharpness of the beam edge or its large penumbra. This is generally manifested by the distance between ( 80 to $20 \%$ ) or (90 to $10 \%$ ) dose at the edge of the beam. The sample data have been published by various authors. It is important to note that there are sizeable differences between penumbras as published in the literatures. These are strongly dependent on both the depth of measurement in water as well as dosimeter type and size. It is clear that for Co-60, the penumbra widths increase with source diameter (e.g. 1.0 to $2.0 \mathrm{~cm}$ ), the distance between the source and the bottom of the field definer and the distance between the field definer and the patient. The x-ray beams from linacs, on the other hand, offer penumbras which are only mildly dependent on geometry due to the small source focal spots (e.g. 0.1 to $0.3 \mathrm{~cm}$ ). However, with increasing x-ray energies, the beam edge is blurred by more energetic electrons scattered in tissue over a greater lateral range. The effective penumbra achieved in the patient is thus significantly enlarged compared with a pure geometric penumbra and it can't be reduced by machine design (Johns et al., 1959).

The radiotherapy center at the $\mathrm{BCH}$, Bhaktapur, Nepal uses $\gamma$ - radiation. The gamma radiation is produced by a single source Cirus cobalt-60 isotope with half-life of 5.26 years. The maximum activity of the source is 20,422 TBq installed in March 2012 (Andreo et al., 2004). The Co-60 source is stored in two heavy metal blocks for shielding the $\gamma$-beam when the machine is in off-position (Opoku et al., 2012). At the storage position, the Co-60 source still undergoes decay and possibly some $\gamma$-radiation leakages out. As many patients are treated in $\mathrm{BCH}$, Bhaktapur, it is necessary to check the output dose of Co-60 units.

Quality assurance (QA) is a program that is designed to check the accuracy of dose delivery mechanism and to ensure proper functioning of the machine. The regular check of all dosimetric parameters of the radiation beam consists of QA. An essential component of QA is dosimetry which is done to ensure that dose output and several factors useful in QA are within an acceptable limit as per the recommendation of American Association of Physics in Medicine (AAPM, 1998). The calibration of the dose output from the radiation beam is very important component in radiotherapy dosimetry because accurate determination of radiation dose is delivered by the treatment machine with respect to time.

ICRU has recommended that the dose delivered should be within $\pm 5 \%$ of the prescribed dose (ICRU, 1996). Considering the many steps involved in delivering dose to a target volume in a patient, each step must be performed with accuracy much better than $\pm 5 \%$ to achieve the ICRU recommendation.

The quality of care should be an intended goal that is to exist in practice before the procedures implemented. QA is a planned or systematic action needed to provide adequate confidence that the radiation oncology service satisfies the given requirement of quality care. The American College of Radiology (Wixenberg et al., 1982; ACR, 19881990) has standards for radiation oncology which specifies a QA program including patient chart review (AAPM, 1971-1993; ACMP, 1986).

\section{MATERIALS AND METHODS}

The dosimetric measurements over a period of three years were performed using the equipments: Farmer Dosimeter 2570/1, Polystyrene Phantom $(20 \mathrm{~cm} \times 20 \mathrm{~cm})$, Thermometer, Aneroid Barometer and 2581 Thimble Chamber $(0.6 \mathrm{cc})$.

Farmer Dosimeter 2570/1 used for the dose measurement is timely calibrated from secondary standard dosimeter in Bhabha Atomic Research Center (BARC) laboratory, India, along with thimble shaped Ion Chambers (Almond, 1981).

The Aneroid Barometer was also calibrated at the time of installation of Cirus Co-60.

Calibrations of Farmer Dosimeter and Thimble Chambers were also performed from BARC. We measured output doses by SSD techniques following IAEA, TRS-398 (2000) protocols for the absorbed dose determination in External Beam Radiotherapy (EBRT) (Andreo et al., 2004). The calibrated Thimble Chamber is placed at the reference depth of $5 \mathrm{~cm}$ in $20 \times 20 \mathrm{~cm}^{2}$ Polystyrene 
Phantom and this chamber is connected with dosimeter. Polystyrene Phantom is fixed at SSD of $80 \mathrm{~cm}$ from the source at $0^{\circ}$ gantry angle and $0^{\circ}$ collimator angle. Then, five readings were taken each for 1 minute, for the reference field size taken as $10 \times 10 \mathrm{~cm}^{2}$.

The absorbed dose rate for Polystyrene at the reference depth is obtained by using the following formula:

Output dose $\left(D_{\text {out }}\right)=\frac{R_{m} \cdot N_{D} \cdot P F \cdot A C F}{P D D D_{5 m}}$

Where,

$\mathrm{R}_{\mathrm{m}}=$ dosimeter reading,

$\mathrm{N}_{\mathrm{D}}=$ chamber calibration factor,

$\mathrm{PF}=$ phantom factor,

$\mathrm{PDD}_{5 \mathrm{~cm}}=$ percentage depth dose $($ for $10 \mathrm{~cm} \times 10 \mathrm{~cm}$ field size for Co-60 the value of PDD at $5 \mathrm{~cm}$ is $78.8 \%)$.

$\mathrm{ACF}=$ ambient correction factor defined by

$\mathrm{ACF}=\frac{273+\mathrm{t}}{273+\mathrm{t}_{0}} \cdot \frac{\mathrm{P}_{0}}{\mathrm{P}}$

Where,

$\mathrm{P}_{0}=$ calibrated pressure, $\mathrm{P}=$ atmospheric pressure,

$\mathrm{t}=$ room temperature, $\mathrm{t}_{0}=$ calibrated temperature.

Here, $\mathrm{P}_{0}$ and $\mathrm{t}_{0}$ are the reference values (generally $1013 \mathrm{mbar}$ and $293 \mathrm{~K}$ ) and phantom factor for Polystyrene Phantom is 1.007 .

The half-life of Co-60 is 5.27 years so that it decays by $1.089 \%$ every month. With multiplying the dose by the factor 0.989 , the expected output for the coming month can be obtained (Baba et al., 2013). The percentage error (PE) for every month is obtained by the relation:

$\mathrm{PE}=\frac{\mathrm{AD}-\mathrm{RD}}{\mathrm{RD}} \times 100 \%$

Where,

$\mathrm{AD}=$ actual output dose and $\mathrm{RD}=$ reference dose.

The graphs were plotted with Origin 5.0.

\section{RESULTS AND DISCUSSION}

We analyzed the distribution of the expected values for the output dose calculated by using the decay method and the actual output measured by the standard techniques for SSD listed in Table 1. The output of the telecobalt unit at the time of source loading, i.e. March 3, 2012 was 203.1cGy/minute for SSD at the position of $80 \mathrm{~cm}$ and the output after one month using decay law was $201.6 \mathrm{cGy} /$ minute for SSD at the same position $(80 \mathrm{~cm})$ for $10 \times 10 \mathrm{~cm}^{2}$ field size.
Figure 1 represents, graphically, the extent of overlap of two dose rates for SSD techniques respectively. With increase in time, the output dose rate has been decreasing continuously.
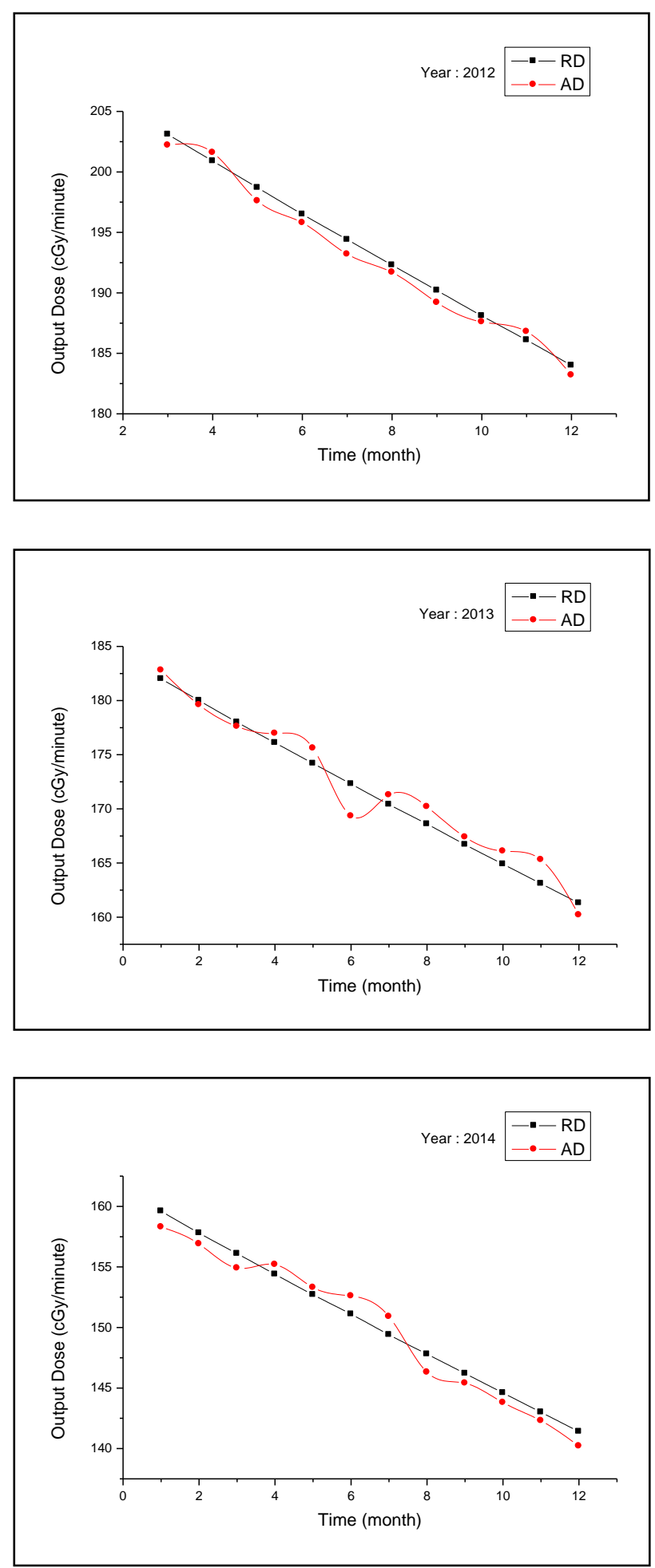

Fig.1. Plots for the output dose rates vs. time for Co-60 TTU comparing actual dose (AD) with reference dose $(R D)$ for the three years data analysis. 
Table1. The comparison between the reference dose (RD) and the output actual dose (AD) in cGy/minute for SSD at the position of $80 \mathrm{~cm}$ from the source since 29 March 2012 to 29 December 2014, i.e. the measurements were done at $29^{\text {th }}$ of each month.

\begin{tabular}{|c|c|c|c|c|c|c|c|c|c|c|c|c|c|}
\hline \multicolumn{2}{|c|}{ Mear } & (1) & $\begin{array}{c}\text { Feb. } \\
(2)\end{array}$ & $\begin{array}{c}\text { March } \\
\text { (3) }\end{array}$ & $\begin{array}{c}\text { April } \\
\text { (4) }\end{array}$ & $\begin{array}{l}\text { May } \\
(\mathbf{5})\end{array}$ & (6) & $\begin{array}{c}\text { July } \\
(7)\end{array}$ & (8) & $\begin{array}{l}\text { Sept. } \\
(9)\end{array}$ & $\begin{array}{l}\text { Oct. } \\
(10)\end{array}$ & $\begin{array}{l}\text { Nov. } \\
(12)\end{array}$ & (13) \\
\hline \multirow[t]{2}{*}{2012} & & & & 203 & 2000 & 198.7 & & & & 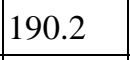 & $x$ & 108 & .0 \\
\hline & AI & & & & & & & & & & & & \\
\hline \multicolumn{2}{|c|}{$\%$ error } & & & & & & & & & & & & \\
\hline \multirow[t]{2}{*}{2013} & & & & & & & & & & & & & \\
\hline & $\mathrm{AI}$ & & & & L & 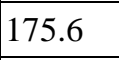 & & & & 1 & & & 60.2 \\
\hline \multicolumn{2}{|c|}{$\%$ error } & .4396 & 22 & & & -0.80 & & & & -0.4199 & & & 682 \\
\hline \multirow[t]{2}{*}{2014} & RD & 506 & 78 & 1 & 4 & 152.7 & & 4 & & 1462 & 14 & 143.0 & 4 \\
\hline & A & & & & 155 & & & & & & & & 2 \\
\hline \multicolumn{2}{|c|}{$\%$ error } & 081 & 5703 & 0.7 & -0. & -0.39 & -0.9921 & 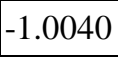 & & 0.5 & 0.5 & & 0.848 \\
\hline
\end{tabular}

It is clear from Table 1 that the percentage error obtained during each year for SSD is less than $\pm 2 \%$ (Johns et al.,1959).

\section{CONCLUSION}

The output dose from Co-60 teletherapy machine was obtained by using actual dosimetry over the periods of 3 years, i.e. 2012 to 2014. Comparing the actual dose to expected output, it has been found that the deviation lies within permissible limits, i.e. $\pm 2 \%$ for each month calculations. The study concludes the quality assurance with the consistency in the output dose delivered by Co-60 TTU, BCH, Nepal, over the period of three years and in turn it shows the accuracy in dose calculations. Furthermore, continuous dosimetric analysis or review process is recommended to check the quality assurance of the therapeutic equipments in identifying their deficiencies and effective corrections.

\section{ACKNOWLEDGEMENT}

We are grateful to Dr. Sudip Shrestha, department of Radiotherapy at $\mathrm{BCH}$, Bhaktapur, Nepal for running QA program.

\section{REFERENCES}

Almond P. R. (1981). Use of a Victoreen 500 Electrometer to Determine Ionization Chamber Collection Efficiencies. Med Phys., 8:901-904.

American Association of Physicists in Medicine (1971). Protocol for the Dosimetry of x-ray and Gamma Ray Beams with Maximum Energies between 0.6 and $50 \mathrm{MeV}$, AAPM, Phys Med Biol., 16(3): 379-396.

American Association of Physicists in Medicine (1983). A Protocol for the Determination of Absorbed Dose from High Energy Photon and Electron Beams. Med Phys., 10:741-771.

American Association of Physicists in Medicine (1984). Physical Aspects of Quality Assurance in Radiation Therapy, Report Series No.13, American Institute of Physics, New York.

American Association of Physicists in Medicine (1984). Symposium Proceedings No.4, Radiotherapy Safety, AAPM, American Institute of Physics, New York.

American Association of Physicists in Medicine (1993). Quality Assurance of Clinical Treatment Planning, Report of Task Group 53 of the Radiation Therapy Committee of AAPM.

American Association of Physicists in Medicine (1998). Radiation Therapy Committee Task Group 53, QA for Clinical Radiotherapy Treatment Planning.

American Association of Physicists in Medicine 1993). Meterset Calculations in Radiotherapy, Report of Task Group 51 of the Radiation Therapy Committee of AAPM.

American College of Medical Physics (1986). Radiation Control and Quality Assurance in Radiation Oncology, ACMP, Rep. Ser. No. 2. 
American College of Radiology (1989). Quality Assurance Program in Radiation Oncology, ACR, Philadelphia.

American College of Radiology (1990). Physical Aspects of Quality Assurance, ACR, Philadelphia.

American College of Radiology (1990). Standards for Radiation Oncology, ACR, Philadelphia.

American Medical Association and American Society of Radiology Technologists (1988). Essentials and Guidelines of an Accredited Education Program for Radiation Therapy Technologists: Description of the Profession, American College of Radiology, ACR.

Andreo P.; Burns D. T.; Braunschweig; Saiful Huq M.; Jefferson T.; Kanai T. et al. (2004). TRS3981 IAEA, Absorbed Dose Determination in External Beam Radiotherapy. An International Code of Practice for Dosimetry Based on Standards of Absorbed Dose to Water, 11b IAEA, WHO, PAHO.

Baba, Misba H.; Mohib-ul-Haq, M., and Khan Aijaz A. (2013). Dosimetric Consistency of Co-60 Teletherapy Unit-a ten years Study. International Journal of Health Sciences, 7(1):15.

International Atomic Energy Agency (2006). Radiation Protection in the Design of Radiotherapy Facilities, Safety Report Series No. 47, IAEA, Vienna.

International Commission on Radiation units and Measurement (1976). Determination of Absorbed Dose in a Patient Irradiated by
Beams of $\mathrm{x}$-ray or $\gamma$-rays in Radiotherapy Procedures, ICRU, Rep.24, Washington D.C., 54.

Johns, H. E., and Cunningham, J. R. (1959). A precession Cobalt-60 Unit for Fixed Field and Rotation Therapy. Amer. J. Roentgen. Rad. Ther. Nucl. Med., 81:4-12.

Kunkler I.; Bomford C. K., and Kunkler, I. H. (2003). Effects of Radiation on Normal Tissues. Walter and Miller's Textbook of Radiotherapy, New York, Churchill LivingStone, 296-306.

Opoku, S. Y. et al. (2012). Re-evaluation of the radiation safety at the teletherapy unit of the Korle Bu Radiotherapy Center, Accra, Ghana. The South African Radiographer, 50(1):9-14.

Prasad K.; Cole W. C., and Haase G. M. (2004). Radiation Protection in Humans: Extending the Concept of As Low As Reasonably Achievable (ALARA) from Dose to Biological Damage. British Journal of Radiology, 77(914): 97-9.

United Nations Scientific Committee on Effects of Atomic Radiation (2010). Sources and Effects of Ionizing Radiation, Report to the General Assembly with Scientific Annexes, Vol. I, UNSCEAR 2008, United Nations Publication, New York.

Wixenberg M. J. (editor) (1982). Quality Assurance in Radiation Therapy: a Manual for Technologists, American College of Radiology, ACR, Philadelphia. 